\title{
Cytogenetics of Oryctes nasicornis L. (Coleoptera: Scarabaeidae: Dynastinae) with Emphasis on Its Neochromosomes and Asynapsis Inducing Premature Bivalent and Chromosome Splits at Meiosis
}

\author{
B. Dutrillaux and A. M. Dutrillaux \\ UMR 7205, OSEB, CNRS/Muséum National d'Histoire Naturelle, 16, rue Buffon, CP 32, 75005 Paris, France
}

Correspondence should be addressed to B. Dutrillaux, bdutrill@mnhn.fr

Received 14 September 2011; Accepted 13 December 2011

Academic Editor: Howard Ginsberg

Copyright ( 2012 B. Dutrillaux and A. M. Dutrillaux. This is an open access article distributed under the Creative Commons Attribution License, which permits unrestricted use, distribution, and reproduction in any medium, provided the original work is properly cited.

\begin{abstract}
The chromosomes of specimens of Oryctes nasicornis from three locations in France and two locations in Greece were studied. All karyotypes have an X-Y-autosome translocation: 18, neoXY. Two male specimens from France (subspecies nasicornis) displayed an unusual behaviour of their meiotic chromosomes in 30-50\% of spermatocytes, with asynapsis at pachynema, premature bivalent and chromosome split at metaphases I and II. The karyotypes remained balanced at metaphase I, but not at metaphase II. These particularities mimic the meiotic behaviour of B chromosomes and question about their existence, reported earlier in Spanish specimens. Due to the variable character of B chromosomes, complementary analyses are needed. To our knowledge, such meiotic particularities have not been described, beside cases of infertility. In specimens from Corsica (subspecies laevigatus) and Greece (subspecies kuntzeni), all spermatocytes I and II had a normal appearance. The meiotic particularity may thus be limited to male specimens from subspecies nasicornis.
\end{abstract}

\section{Introduction}

Beside pathological conditions such as malignancies or chromosome-instability syndromes, intraindividual variations of chromosomes are rare. Because of its usual stability, the karyotype of a limited number of cells is thought to represent that of a whole individual. This stability prevails for germ cells, so that parental and descendant karyotypes are similar. Consequently, the chromosome analysis of a limited number of cells from a limited number of individuals most frequently gives valuable information about the karyotype of their species. Exceptions exist, however, among which the presence of $\mathrm{B}$ chromosomes represents a major cause of numerical variation and polymorphism. B chromosomes have been described in plants and animals. They are characterized by a number of criteria among which is their particular meiotic behaviour: they do not pair like autosomes and tend to undergo premature centromere cleavage and non-disjunction at anaphase.
This leads to variations of their number from cell to cell and descendant to descendant [1].

Insect cytogenetics has essentially been developed through spontaneously dividing germ cells at diakinesis/metaphase I and metaphase II. At these stages, chromosome morphology is not optimal for analysis. Among several thousand of chromosome formulas reported in coleopterans, the presence of B chromosomes was noticed in about 40 instances [1-5]. Oryctes nasicornis L. 1758 (Coleoptera: Scarabaeidae: Dynastinae) is one of the very first insects in which dispensable supernumerary chromosomes were described [6] and later on considered as B chromosomes. This observation was quoted in reviews on both insect cytogenetics $[5,6]$ and B chromosomes [1].

Having analysed the mitotic chromosomes of a male specimen of $O$. nasicornis L. 1758, we were surprised to observe a karyotype different from its earlier descriptions. It had neither a Xyp (p for parachute, [6]) sex formula nor 
supernumerary $\mathrm{B}$ chromosomes, but neoXY as a consequence of an X-Y-autosome translocation. B chromosomes being dispensable, we studied specimens from other localities and performed meiotic analyses to understand the causes of these discrepancies. We did not find B chromosomes, but, in two out of seven specimens, there were quite unexpected meiotic particularities. From pachytene to spermatocyte II stages, recurrent asynapsis, nonpairing, and premature centromeric cleavages mimic the behaviour of B chromosomes. Checkpoints controlling meiotic chromosome behaviour have been identified, from yeast to mammals $[7,8]$. They monitor elimination of spermatocytes with abnormal chromosome synapsis [9]. In some Oryctes nasicornis specimens, the anomalies at metaphase I and II, as consequences of pachytene asynapsis, suggest the low stringency of these checkpoints.

\section{Material and Methods}

Two male specimens (number 1 and 2) of O. nasicornis were obtained from the breeding developed at the Museum of Besançon (France). They were captured as larvae in the Besançon area and are assumed to correspond to the nasicornis subspecies. They metamorphosed in June 2006. Two adult male specimens were captured in April 2007 (specimen number 3) and September 2010 (specimen number 4), at Bois-leRoi, at the Fontainebleau forest border $\left(48^{\circ} 27^{\prime} \mathrm{N}, 2^{\circ} 42^{\prime} \mathrm{E}\right)$. They are assumed to belong also to the nasicornis subspecies. Another male (specimen number 5) was captured near Porto Vecchio, Corsica $\left(41^{\circ} 36^{\prime} \mathrm{N}, 9^{\circ} 11^{\prime} \mathrm{E}\right)$, in June 2007. It is assumed to belong to the laevigatus Heer 1841 subspecies. Finally, two males were captured in Greece, one (specimen number 6) near Oros Kallidromo $\left(38^{\circ} 44^{\prime} \mathrm{N}, 22^{\circ} 39^{\prime} \mathrm{E}\right)$ in may 2010 and one (specimen number 7) near Kalambaka $\left(39^{\circ} 47^{\prime} \mathrm{N}, 21^{\circ} 55^{\prime} \mathrm{E}\right)$ in June 2011 . They are assumed to belong to the kuntzeni Minck subspecies. Pachytene bivalent chromosome preparations were obtained following a long hypotonic shock and meiotic and mitotic metaphases after treatment with O.88 M KCL for $15 \mathrm{~min}$. and another $15 \mathrm{~min}$. in diluted calf serum $(1 \mathrm{vol}$.) in distilled water $(2$ vol. $)$ [10, 11]. Chromosomes at various mitotic and meiotic stages were studied after Giemsa and silver stainings and Q- and C-banding. Image capture was performed on a Zeiss Phomi 3 equipped with a high-resolution camera JAI M4+ and IKAROS (Metasystems) device or a Leica Aristoplan equipped with a JAI M300 camera and ISIS (Metasystems) device.

\section{Results}

Mitotic Karyotype (Figure 1). It is composed of 18 chromosomes, including three sub-metacentric (number 1, 2 and 8) and five acrocentric (number 3-7) autosomal pairs. All of them carry large and variable heterochromatic segments around the centromeric region. The $\mathrm{X}$ chromosome is submetacentric and the $\mathrm{Y}$ acrocentric. Their size is much larger than that of gonosomes of most other Scarabaeid beetles. All heterochromatin is positively stained after C-banding and heterogeneously stained after Q-banding (not shown) which

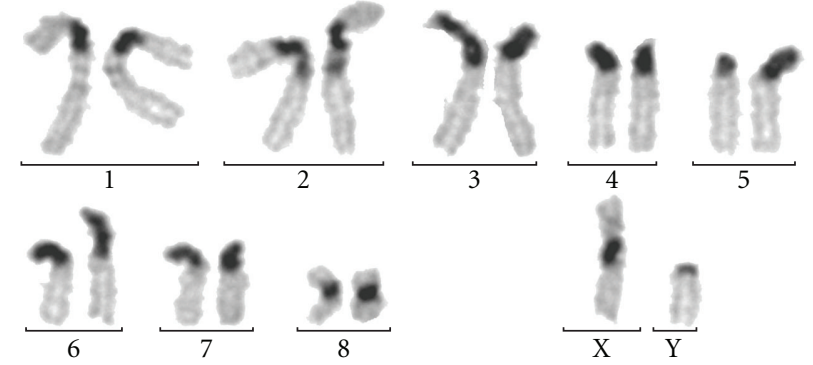

Figure 1: Mitotic karyotype of Oryctes nasicornis male (specimen number 1 from Besançon) after C-banding.

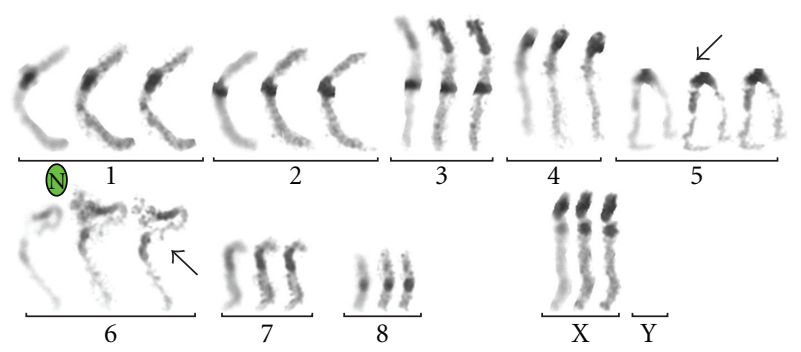

Figure 2: Karyotype from a spermatocyte at pachynema after the Giemsa staining (left), NOR staining displaying nucleoli (N) (centre), and C-banding treatment (right). Acrocentric bivalents 5 and 6 are not synapsed, but associated by their heterochromatic short arms (arrows). Heterochromatin is more compact than on mitotic chromosomes. Specimen number 3 from Bois-le-Roi, as is the case in the next figures.

indicates its heterogeneous composition. Beside the variations of the amounts of heterochromatin, all specimens had the same chromosome complement, as reported $[4,12]$.

Pachytene Chromosomes (Figures 2 and 3). As expected from the mitotic karyotype, nine bivalents were generally observed. They could be identified by the amount and position of their heterochromatin, although heterochromatin was globally more compact than in mitotic cells. The sex bivalent was quite characteristic. It had a large synapsed segment, similarly to autosomes, followed by juxtacentromeric heterochromatin, and a compact segment. This was interpreted as the result of an X-Y-autosome translocation, the autosomal portion forming the long arm and the sex chromosomes forming the short arm. This translocation explains the low number of chromosomes (18 instead of 20 in most Scarabaeidae) and the large size of the sex chromosomes (the short arm relative length matches that of the $\mathrm{X}$ of other Dynastinae with a free $\mathrm{X})$. Thus, the mitotic karyotype formula is 18 , neoXY. Silver staining displayed a strong staining of all heterochromatin, as in most coleopterans. In addition, round nucleolar-like structures were recurrently associated with the short arm of a small acrocentric bivalent that we defined as number 6 . Thus, according to previous studies [13], the Nucleolar Organizer Region (NOR) is located on chromosome 6 short arm (Figure 2). The above description refers to observed spermatocytes. However, one or several bivalents displayed 

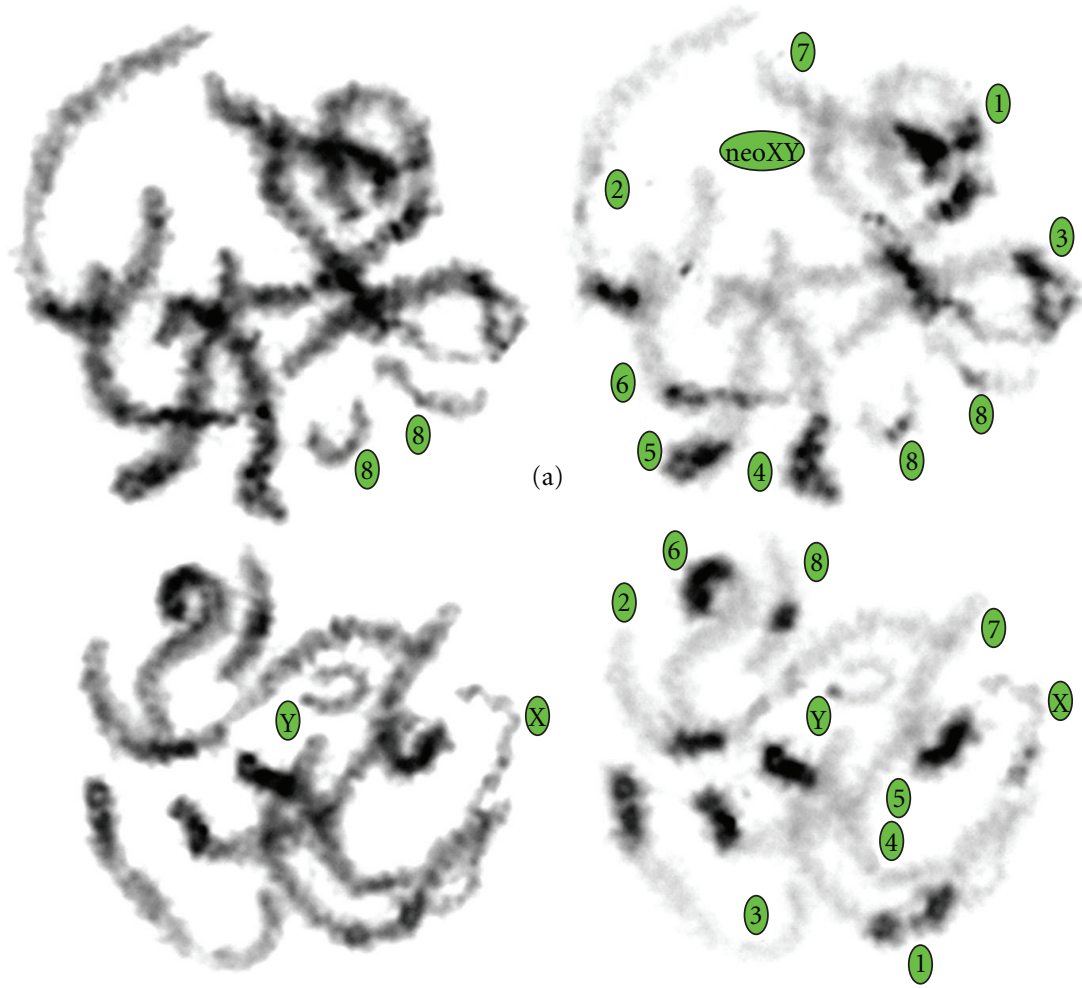

(b)

FIGURE 3: Spermatocytes at pachynema after the Giemsa staining (left) and C-banding (right) displaying asynapsis of chromosomes 8 (a) and sex chromosomes (b).

either asynapsis or incomplete synapsis in $29 \%$ and $41 \%$ of the spermatocytes from specimen number 2 and 3 from Besançon and Bois-le-Roi, respectively (Table 1). Smaller acrocentrics (numbers 6 and 7) were the most frequently involved, but all bivalents, including the sex bivalent (Figures 2, 3(a) and 3(b)), could be occasionally affected. In all instances, the non-synapsed autosomes were lying close to each other, suggesting either their premature desynapsis or deficient synapsis. The two homologues remained frequently at contact by their heterochromatic regions (Figure 2). Conversly the neoX and neoY chromosomes could be completely separated (Figure 3(b)). Specimen number 1 was immature and spermatocytes at pachynema of specimen number 5 could not accurately be studied and could not be considered as control. In specimen number 4 from Bois-le-Roi and specimens number 6 and 7 from Greece, the synapsis was strictly normal. We applied the same cytological techniques to specimens from more than other 100 species and observed such pachytene asynapsis only once and at a low frequency.

Diakinesis/Metaphase I (Figure 4). This stage was the most frequent in all the specimens studied: a total of 696 cells could be examined. Most of them displayed nine bivalents (biv), among which the sex bivalent could be identified by its asymmetrical constitution, as in other species with translocation-derived neoXY. No particularities were noticed in specimens number 4 to 7 , whereas $43 \%$ and $34 \%$ of cells from the specimens number 2 and 3 (Table 1) displayed uni-
TABle 1: Numbers and percentages of mitotic and meiotic cells analysed in specimen number 2 from Besançon and number 3 from Bois le Roi. Cells were scored as abnormal (abnl) when they displayed asynapsis (pachynema), univalents (diakinesis/metaphase I) or monochromatidic chromosomes (metaphase II), and normal (nl), when all chromosomes were in correct phase.

\begin{tabular}{lcccccc}
\hline Cell stage & \multicolumn{3}{c}{ Besançon-image no. 2 } & \multicolumn{3}{c}{ Bois-le-Roi-image no. 3 } \\
& $\mathrm{nl}$ & $\mathrm{abnl}$ & $\%$ abnl & $\mathrm{nl}$ & abnl & $\%$ abnl \\
\hline Mitotic & 32 & 0 & 0 & 5 & 0 & 0 \\
$\begin{array}{l}\text { Metaphase } \\
\text { Pachynema }\end{array}$ & 34 & 10 & 29 & 36 & 25 & 41 \\
$\begin{array}{l}\text { Diakinesis/ } \\
\text { Metaphase I }\end{array}$ & 41 & 31 & 43 & 195 & 99 & 34 \\
$\begin{array}{l}\text { Diakinesis/ } \\
\text { Metaphase II }\end{array}$ & 25 & 11 & 31 & 40 & 58 & 59 \\
\hline
\end{tabular}

valents (univ), respectively. Their number was inversely proportional to that of bivalents: 9 biv +0 univ; 8 biv +2 univ; 7 biv +4 univ; 6 biv +6 univ, demonstrating that two univalents replaced one bivalent. The univalent occurrence, observed at both early diakinesis and late metaphase I, did not seem to depend on the progression towards anaphase. It preferentially involved smaller and sex chromosomes.

Metaphase II (Figures 5 and 6). No particularities were noticed among the 56, 48, 50 and 27 metaphases II analyzed 


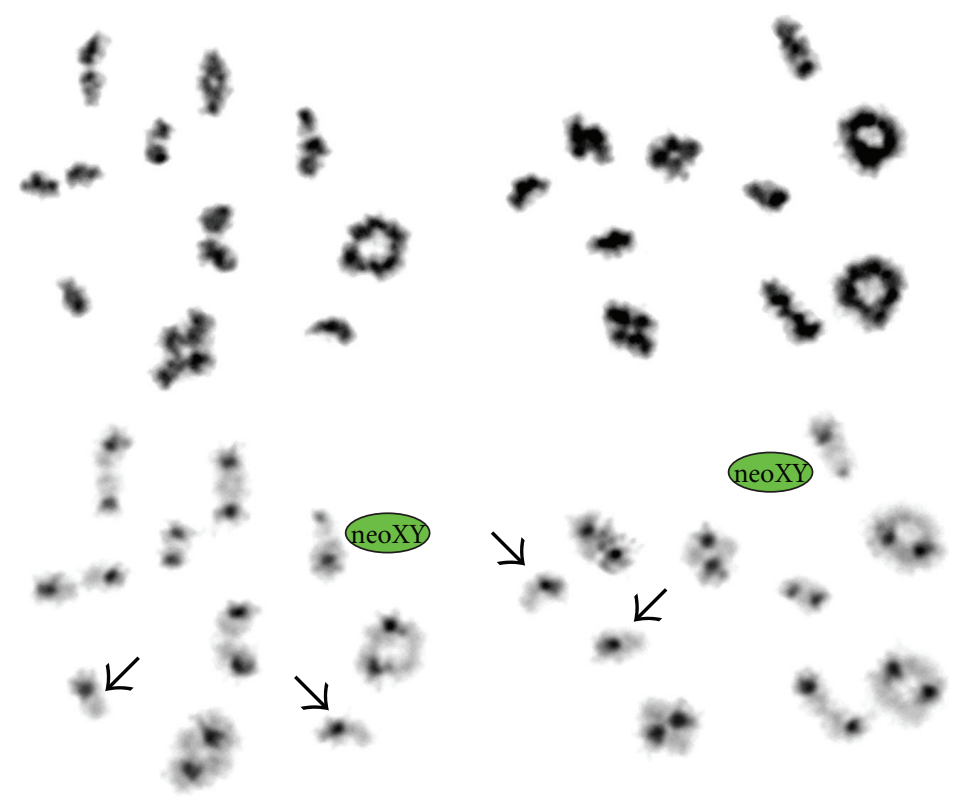

Figure 4: Spermatocytes at metaphase I after the Giemsa staining (top) and C-banding (bottom) with eight bivalents and two univalents (arrows).

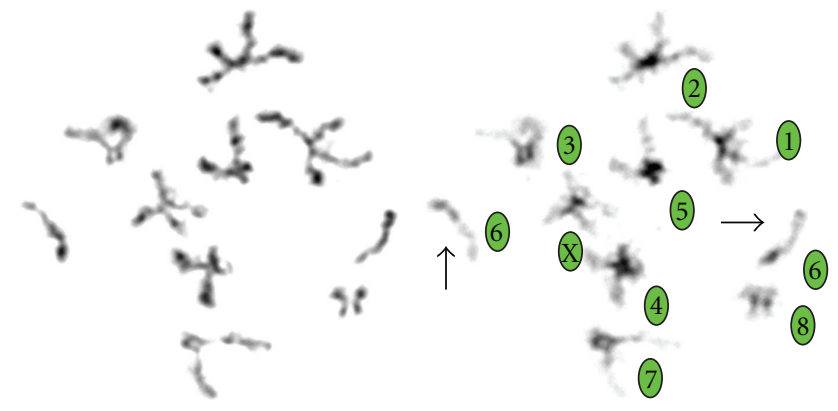

FIGURE 5: Spermatocyte at metaphase II displaying eight bi-chromatidic and two single-chromatid chromosomes, presumably number 6 (arrows).

from specimens 4, 5, 6, and 7, respectively. All were composed of 9 double-chromatid chromosomes. In specimens 2 and 3, 31\% and 59\% of metaphases II, respectively, comprised more than 9 chromosomes. C-banding allowed us to differentiate mono-chromatidic (monoc) and bi-chromatidic (bic) chromosomes. The number of monoc was roughly inversely proportional to that of bic: 9 bic +0 monoc, 8 bic +2 monoc (Figure 5), 7 bic +4 monoc, and 6 bic +6 monoc. In a proportion of metaphases II, however, the ratio bic/ monoc was different, indicating that aneuploidies occurred, as consequence of segregation errors at anaphase I (Figure 6). The premature centromeric split preferentially involved the small acrocentrics, the metacentric 8 , and the sex chromosomes.

\section{Discussion}

The karyotypes of the specimens of $O$. nasicornis studied here obviously do not contain B chromosomes. O. nasicornis is a widespread species in Western Europe, with eleven subspecies identified. The first mention of its karyotypic particularities was reported on Spanish specimens, which belong to the grypus Illiger 1803 subspecies [4]. The specimens from Besançon and Bois-le-Roi belong to the subspecies nasicornis. These two locations cover only a small part of the whole distribution area of the subspecies, but they are sufficiently distant (about $300 \mathrm{~km}$ ) to assume that they do not constitute an isolate with abnormal gametogenesis. The specimens from Corsica and Greece, in which we failed to detect any meiotic particularity, belong to the subspecies laevigatus and kuntzeni, respectively, and there are no available data on the chromosomes of other specimens from this subspecies. Thus, the question of both the presence of B chromosomes and/or atypical meiosis, in relation with subspecies, remains open and needs further investigations.

The high recurrence of asynapsis and premature centromeric cleavage may be an artifact induced by hypotonic shock and spreading. However, the techniques used for pachynema and other meiotic stages were different, and we found fairly similar rates of aberrations at all stages. Furthermore, technical artifacts can hardly explain aneuploidies at metaphase II. We applied these techniques on meiotic chromosomes from many species of coleopterans without B chromosomes and observed such particularities only once at a low rate. Conversly, when $\mathrm{B}$ chromosomes were duly identified, they had a particular pairing leading to non-disjunctions at anaphase I, hence duplications and losses in spermatocytes II and variable numbers in descendants. It has no effect upon the phenotype, which indicates they carry no genes with major effect on the phenotype [1]. Here, all chromosomes can be involved in abnormal meiotic pairing. At metaphase II, $30-50 \%$ of spermatocytes displayed premature chromosome cleavage, which should induce a high rate of 


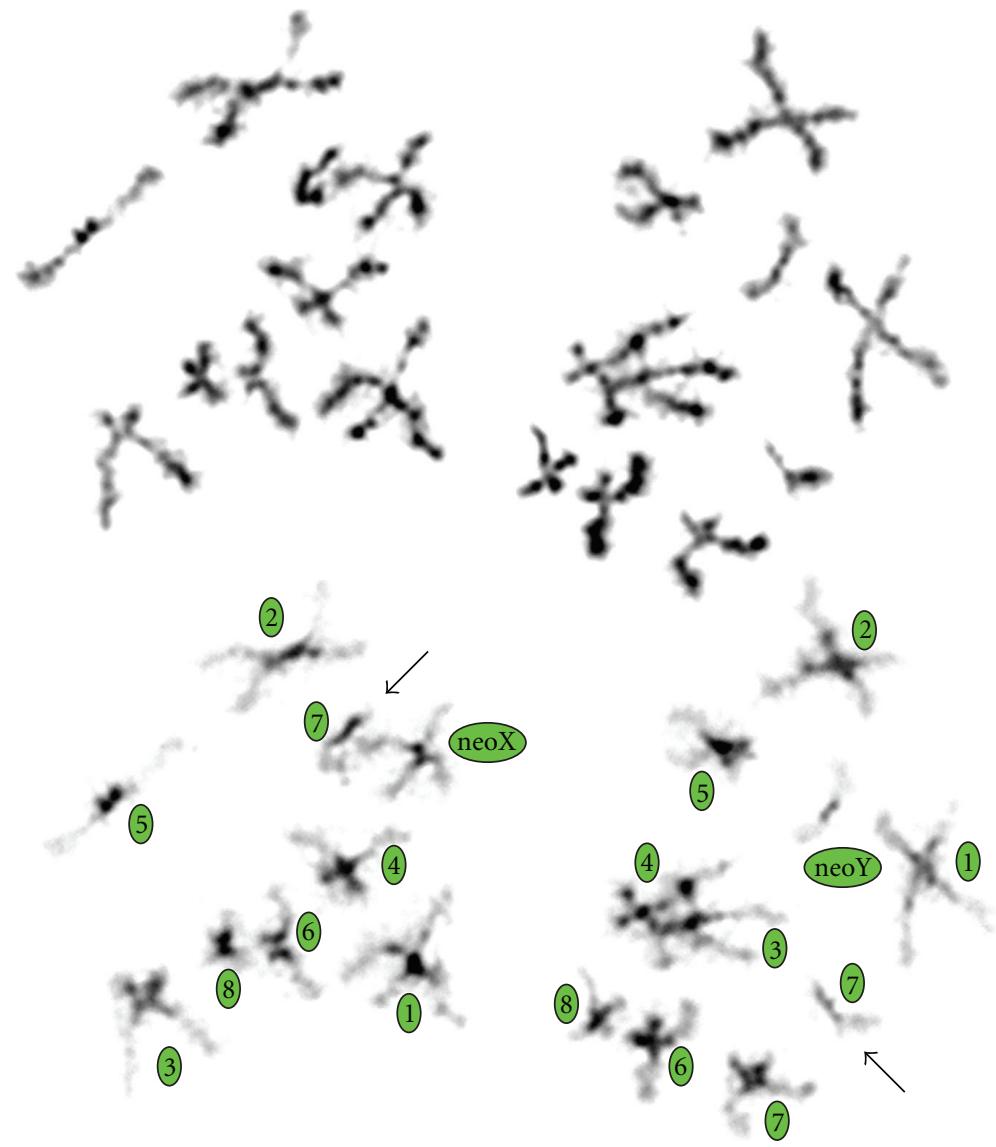

FIGURE 6: Unbalanced sister metaphases II after the Giemsa staining (top) and C-banding (bottom). One acrocentric (presumably number 7) is single-chromatid on the left, while the complementary mono-chromatidic chromosome is in excess on the right (arrows).

unbalanced gametes. Indeed, aneuploid spermatocytes II were observed and a reduction of reproductive fitness should be expected, but we have no indication that it is the case. Furthermore, it is noteworthy that the rates of asynapsis at pachynema, premature bivalent cleavage at metaphase I, and premature centromere split at metaphase II are roughly similar at both intra- and interindividual levels. This suggests that metaphase I and II anomalies are direct consequences of pachytene asynapsis, and that there is both synapsis and checkpoint flaws at pachynema $[8,9]$. It will be interesting to establish karyotypes of a series of eggs laid by parents with these meiotic particularities to know whether or not they induce a high rate of aneuploidies at early stages of development.

Another point of interest, in the karyotype of O.nasicornis, is the presence of neo-sex chromosomes. As described in the Scarabaeid beetles Dynastes hercules and Jumnos ruckeri, their meiotic behaviour, with an autosome-like synapsis of a long portion, indicates they originated from an X-Y-autosome translocation $[13,14]$. As in these species too, the autosomal portion is separated from the original X component by the centromere, that is, constitutive heterochromatin. The insulating role of heterochromatin has been discussed for long in mammals, where it prevents inactivation spreading from the late replicating $\mathrm{X}$ to the attached autosome in female somatic cells [15]. In meiotic prophase of the male, heterochromatin also isolates euchromatin from the inactivated sex chromosomes [16]. In Drosophila, the gene dosage compensation between males and females somatic cells is achieved by the overexpression of genes from the single $\mathrm{X}$ of the males [17]. This may also be the case of the beetle Dynastes hercules, but this was shown only for NOR expression [13]. In Gryllotalpa fossor (Orthoptera), the dosage compensation is of the mammalian type [18]. Finally, in Musca domestica (Diptera), no dosage compensation seems to exist [19]. These different situations demonstrate the existence of several regulatory mechanisms for X-linked gene expression in insect somatic cells. Whatever this mechanism, that is, over- or underexpression, there is an important character which is the existence of an epigenetic control spreading over large chromosome segments, if not whole chromosomes. We proposed that, in insects with overexpression of the X-linked genes in the male, as Drosophila, heterochromatin might play this insulating role [13]. This fits with the observation that in the few instances where an $\mathrm{X}$-autosome translocation carrier Drosophila is fertile, the break point originating the translocation occurred within heterochromatin of the X ([20] and references herein). The presence of heterochromatin between gonosomal and autosomal components in the neo-sex chromosomes of $O$. nasicornis provides another example 
suggesting the role of heterochromatin to avoid spreading of cis-acting epigenetic control elements.

In conclusion, this study shows that two chromosomal particularities exist in O. nasicornis. One is an X-Y-autosome translocation, frequently deleterious for reproduction, unless specific conditions prevent position effect, due to the different regulation of sex chromosomes and autosomes. Such translocations are not exceptional in Coleoptera, compared to other animals such as mammals. The other particularity is much more exceptional: two male specimens of $O$. nasicornis nasicornis display meiotic alterations usually considered as deleterious for fertility. These specimens were caught at two distant localities, which suggests these alterations are spread in the population and do not drastically prevent reproduction. Progress in the molecular biology of meiosis has shown the multiplicity of genes involved in synaptonemal complex formation and recombination $[21,22]$. One of them may be altered in some specimens of $O . n$. nasicornis and maintained if associated with some hypothetical advantage. A third particularity, that is, the presence of B chromosomes, reported in specimens from Spain, may be an incorrect interpretation of the meiotic particularity described here and warrants further studies.

\section{Acknowledgments}

The authors are indebted to Jean-Yves Robert and Frédéric Maillot, Muséum de Besançon, France, and Laurent Dutrillaux, who provided us with the specimens from Besançon area and Corsica, respectively.

\section{References}

[1] R. N. Jones and H. Rees, B Chromosomes, Academic Press, London, UK, 1982.

[2] C. Juan and E. Petitpierre, "Chromosome numbers and sex determining systems in Tenebrionidae (Coleoptera)," in Advances in Coleopterology, M. Zunino, X. Belles, and M. Blas, Eds., pp. 167-176, AEC Press, Barcelona, Spain, 1991.

[3] E. Petitpierre, C. Segara, J. S. Yadav, and N. Virkki, "Chromosome numbers and meioformulae of chrysomelidae," in Biology of Chrysomelidae, P. Jolivet, E. Petitpierre, and T. H. Hsiao, Eds., pp. 161-186, Kluwer Academic Publishers, Dodrecht, The Netherlands, 1988.

[4] N. Virkki, "Akzessorische chromosomen bei zwei käfern, Epicometis hirta und Oryctes nasicornis L. (Scarabaeidae)," Annales Academice Scientiarum Fennice, vol. 26, pp. 1-19, 1954.

[5] J. S. Yadav, R. K. Pillai, and Kaaramjeet, "Chromosome numbers of Scarabaeidae (Polyphaga: Coleoptera)," The Coleopterist Bulletin, vol. 33, pp. 309-318, 1979.

[6] S. G. Smith and N. Virkki, Insecta 5: Coleoptera, vol. 3 of Animal Cytogenetics, Gebrüder Borntraeger, Berlin, Germany, 1978.

[7] N. Bhalla and A. F. Dernburg, "Cell biology: a conserved checkpoint monitors meiotic chromosome synapsis in Caenorhabditis elegans," Science, vol. 310, no. 5754, pp. 16831686, 2005.

[8] H. Y. Wu and S. M. Burgess, "Two distinct surveillance mechanisms monitor meiotic chromosome metabolism in budding yeast," Current Biology, vol. 16, no. 24, pp. 2473-2479, 2006.
[9] G. S. Roeder and J. M. Bailis, "The pachytene checkpoint," Trends in Genetics, vol. 16, no. 9, pp. 395-403, 2000.

[10] A. M. Dutrillaux, D. Pluot-Sigwalt, and B. Dutrillaux, “(Ovo-)viviparity in the darkling beetle, Alegoria castelnaui (Tenebrioninae: Ulomini), from Guadeloupe," European Journal of Entomology, vol. 107, no. 4, pp. 481-485, 2010.

[11] A. M. Dutrillaux, S. Moulin, and B. Dutrillaux, "Use of meiotic pachytene stage of spermatocytes for karyotypic studies in insects," Chromosome Research, vol. 14, no. 5, pp. 549-557, 2006.

[12] A. M. Dutrillaux and B. Dutrillaux, "Sex chromosome rearrangements in polyphaga beetles," Sexual Development, vol. 3 , no. 1, pp. 43-54, 2009.

[13] A. M. Dutrillaux, J. Mercier, and B. Dutrillaux, "X-Y-autosome translocation, chromosome compaction, NOR expression and heterochromatin insulation in the Scarabaeid beetle Dynastes hercules hercules," Cytogenetic and Genome Research, vol. 116, no. 4, pp. 305-310, 2007.

[14] N. Macaisne, A. M. Dutrillaux, and B. Dutrillaux, "Meiotic behaviour of a new complex X-Y-autosome translocation and amplified heterochromatin in Jumnos ruckeri (Saunders) (Coleoptera, Scarabaeidae, Cetoniinae)," Chromosome Research, vol. 14, no. 8, pp. 909-918, 2006.

[15] J. Couturier and B. Dutrillaux, "Replication studies and demonstration of position effect in rearrangements involving the human X chromosome," in Cytogenetics of Human X Chromosome, A. Sandberg and A. Liss, Eds., pp. 375-403, 1983.

[16] C. Ratomponirina, E. Viegas-Pequignot, and B. Dutrillaux, "Synaptonemal complexes in Gerbillidae: probable role of intercalated heterochromatin in gonosome-autosome translocations," Cytogenetics and Cell Genetics, vol. 43, no. 3-4, pp. 161-167, 1986.

[17] V. Gupta, M. Parisi, D. Sturgill et al., "Global analysis of Xchromosome dosage compensation," Journal of Biology, vol. 5, article 3, 2006.

[18] S. R. V. Rao and M. Padmaja, "Mammalian-type dosage compensation mechanism in an insect -Gryllotalpa fossor (Scudder)- Orthoptera," Journal of Biosciences, vol. 17, no. 3, pp. 253-273, 1992.

[19] A. Dübendorfer, M. Hediger, G. Burghardt, and D. Bopp, "Musca domestica, a window on the evolution of sex-determining mechanisms in insects," International Journal of Developmental Biology, vol. 46, no. 1, pp. 75-79, 2002.

[20] M. Ashburner, Drosophila: A Laboratory Handbook, Cold Spring Harbor Laboratory Press, Cold Spring Harbor, NY, USA, 1989.

[21] M. D. Champion and R. S. Hawley, "Playing for half the cleck: the molecular biology of meiosis," Nature Cell Biology, vol. 4, pp. 50-56, 2002.

[22] P. E. Cohen, S. E. Pollack, and J. W. Pollard, "Genetic analysis of chromosome pairing, recombination, and cell cycle control during first meiotic prophase in mammals," Endocrine Reviews, vol. 27, no. 4, pp. 398-426, 2006. 

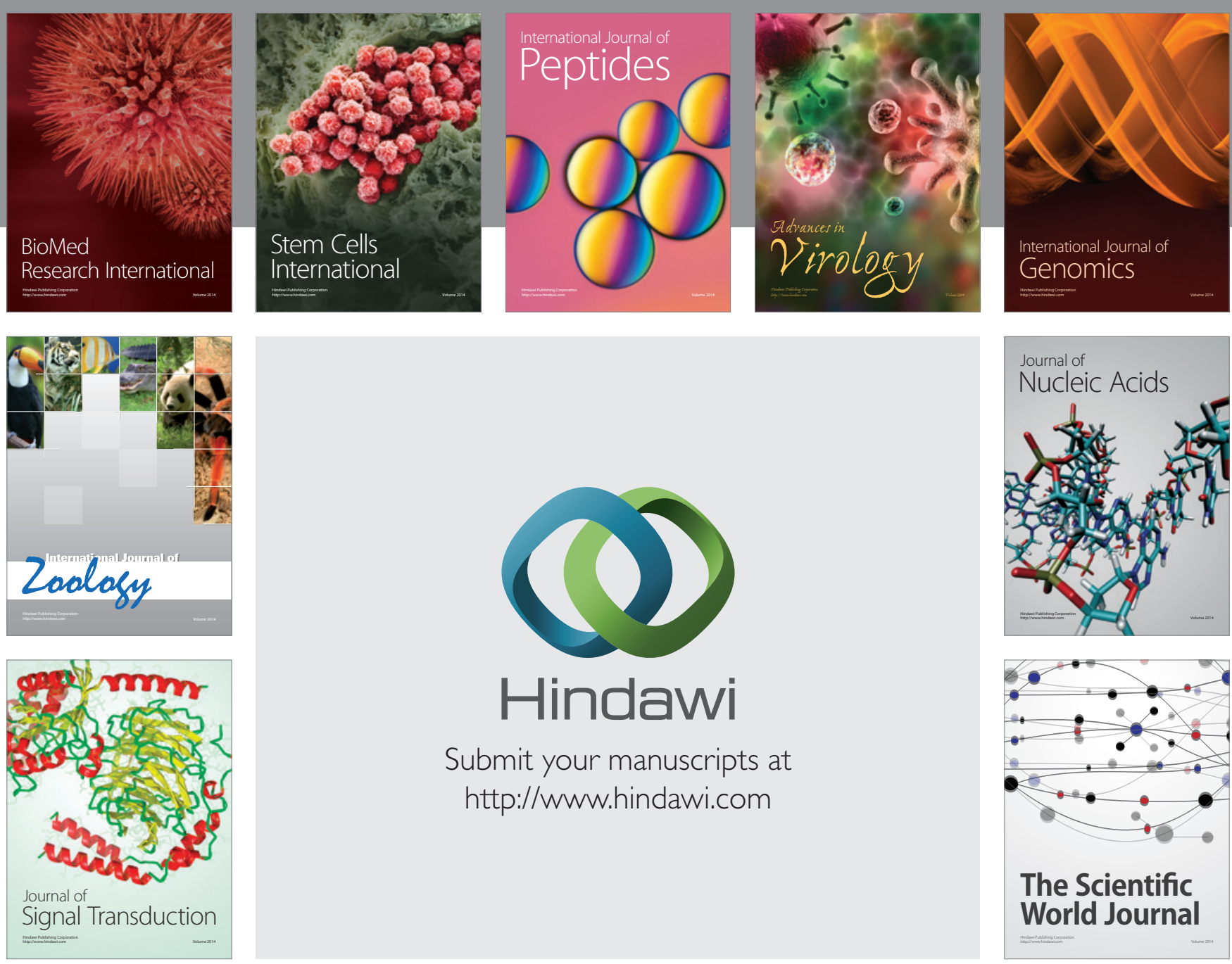

Submit your manuscripts at

http://www.hindawi.com
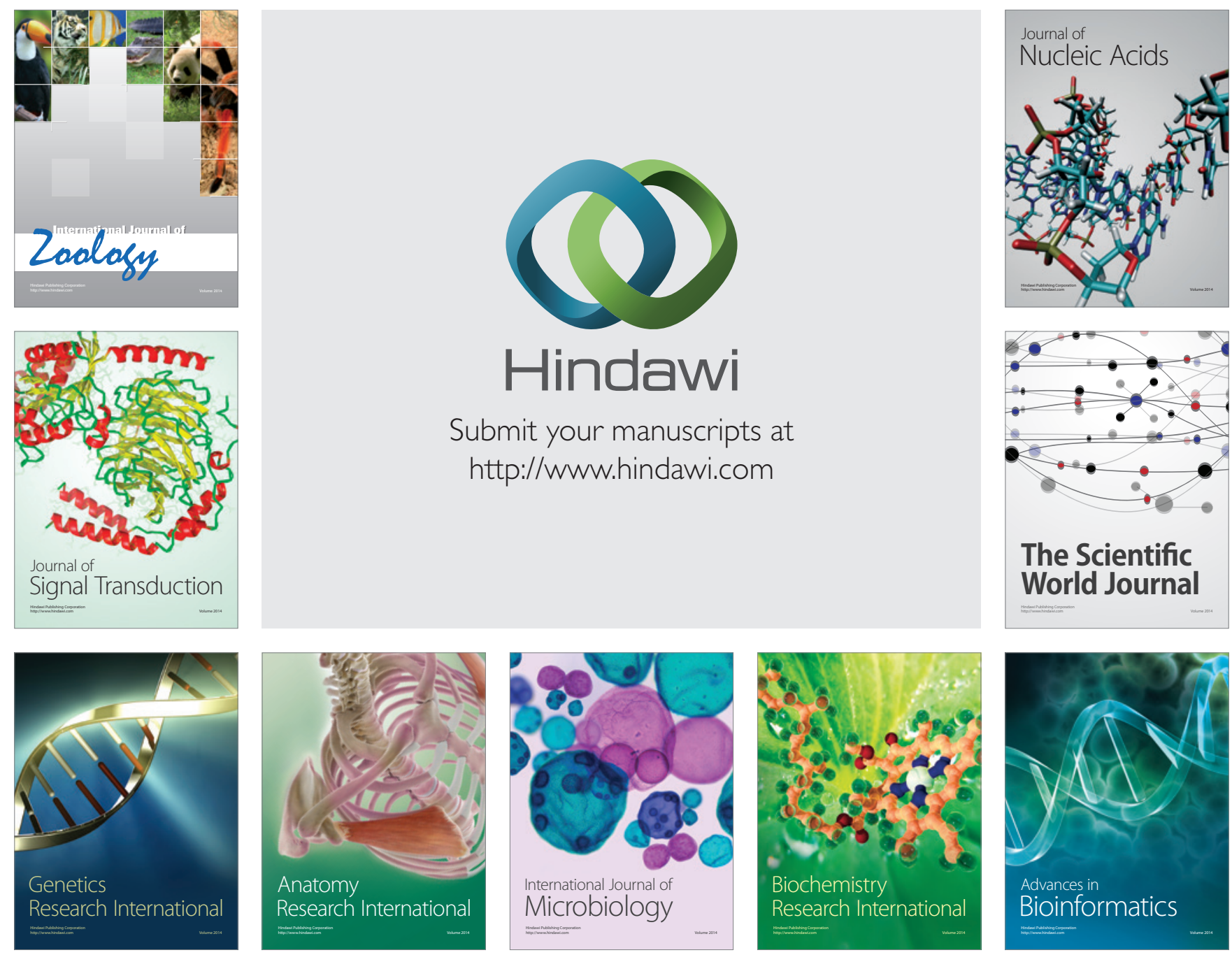

The Scientific World Journal
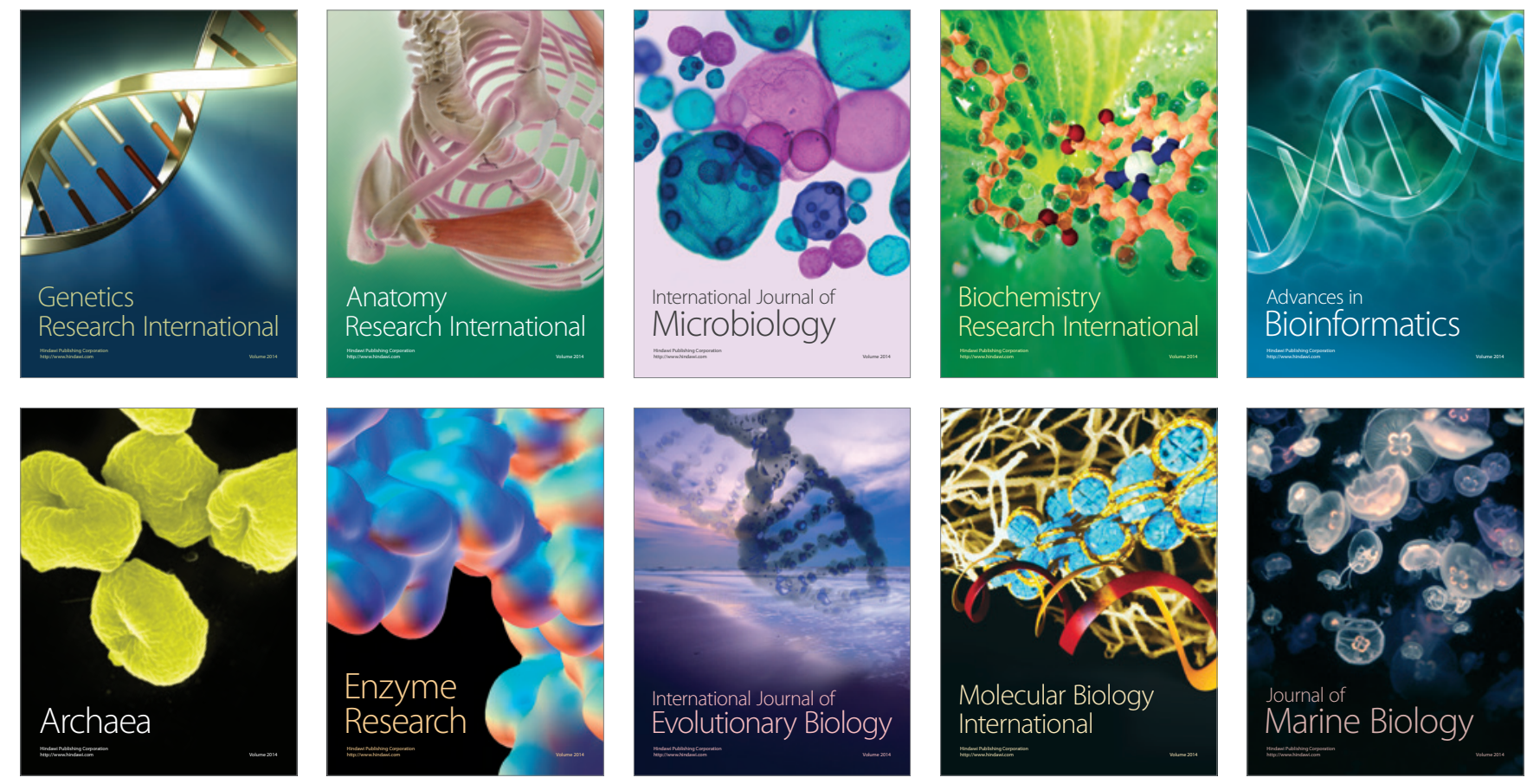